\title{
Numerical Simulation of Projectile Impact on Mild Steel Armour Plates using LS-DYNA, Part II: Parametric Studies
}

\author{
M. Raguraman ${ }^{1}$, A. Deb ${ }^{1}$, N.K. Gupta ${ }^{2}$, and D.K. Kharat ${ }^{3}$ \\ ${ }^{1}$ Indian Institute of Science, Bangalore-560 012 \\ ${ }^{2}$ Indian Institute of Technology Delhi, New Delhi-110 016 \\ ${ }^{3}$ Armament Research \& Development Establishment,Pune-411 021
}

\begin{abstract}
In Part I of the current two-part series, a comprehensive simulation-based study of impact of jacketed projectiles on mild steel armour plates has been presented. Using the modelling procedures developed in Part I, a number of parametric studies have been carried out for the same mild steel plates considered in Part I and reported here in Part II. The current investigation includes determination of ballistic limits of a given target plate for different projectile diameters and impact velocities, and effects of plate thickness and projectile parameters such as mass, diameter and nose shape on residual velocity. In all cases studied, trends consistent with earlier experimentally-observed behaviours for similar impact problems have been found, thereby establishing the potential of the present simulation technique using LS-DYNA as a powerful tool for the design of steel armour plates.
\end{abstract}

Keywords: Simulation, LS-DYNA, parametric study, mild steel plate, projectile, ballistic limit, numerical simulation, modelling and simulation, Belytschko-Lin-Tsay shell, BLT shell, residual velocity

\section{INTRODUCTION}

In Part I of the present two-part series, detailed modelling guidelines for simulation of ballistic impact on mild steel target plates by jacketed ogival-nosed projectiles have been reported. The modelling criteria developed include desirable element size for target plate discretization with Belytschko-Lin-Tsay (BLT) shell, constant stress solid, or axisymmetric elements, contact condition, and strain rate-dependent material properties. Using these criteria, a number of parametric studies were carried out by representing plates with BLT shell elements as these are computationally efficient and can well predict residual velocity as well as plate failure mode. To start with, the effect of plate thickness on residual velocity is shown for
MS1, MS2 and MS3 plates ${ }^{1}$. This is followed up with a study on the effects of projectile diameter (with constant shank length-to-diameter ratio) and mass on residual velocity. The trends of ballistic limit and residual velocity variation obtained in these investigations are consistent with the test-based behaviours reported for similar situations ${ }^{2}$. Finally, the influence of projectile nose shape is studied using the three-plate discretisation approache outlined in Part I, and although the most consistent behaviour is obtained for the axisymmetric modelling of projectile and target plate, all the three approaches confirmed the experimental observation made by Raguraman and $\mathrm{Deb}^{3}$ that conical-nosed projectiles require the lowest perforation energy at higher impact velocities. 


\section{NUMERICAL PARAMETRIC STUDIES}

The results presented in Part I of the paper clearly show that BLT shell elements combined with strain rate-based constitutive modelling with load curves can be used for representing ballistic impact on mild steel target plates. Using the geometric and material modelling procedure developed in Part I of this paper (such as shell element size of $1.5 \mathrm{~mm}$ with CESS interface), numerical parametric studies were carried out to demonstrate the usefulness of the present simulation methodology as a tool for designing penetration-resistant armour plates.

\subsection{Effect of Plate Thickness on Residual Velocity}

To carry out a rational study on the effect of plate thickness on residual velocity, all projectile and plate parameters, except plate thickness, should be maintained as constant. To this end, singlelayered plates ${ }^{1}$ of five different thickness, viz., 4.7 $\mathrm{mm}, 6 \mathrm{~mm}, 10 \mathrm{~mm}, 12 \mathrm{~mm}$, and $16 \mathrm{~mm}$ studied experimentally in ${ }^{1}$ were considered; however unlike in $^{1}$ in which $4.7 \mathrm{~mm}$ and $6 \mathrm{~mm}$ plates were of grade MS1 and MS2, respectively, while the remaining plates were of grade MS3; in the present case, plates of all five gages were at a time assigned the same grade MS1, MS2 or MS3. Thus, a total of 15 cases had to be analysed and the results are given in Fig. 1. For each series of plates of a given material type (i.e., MS1, MS2 or MS3), the best-fit curve for residual velocity versus plate thickness has also been drawn. It is worthwhile to note from Fig. 1 that MS1 plates, being weaker than MS2 and MS3 plates, yielded highest residual velocities, while MS2 plates performed the best especially at higher

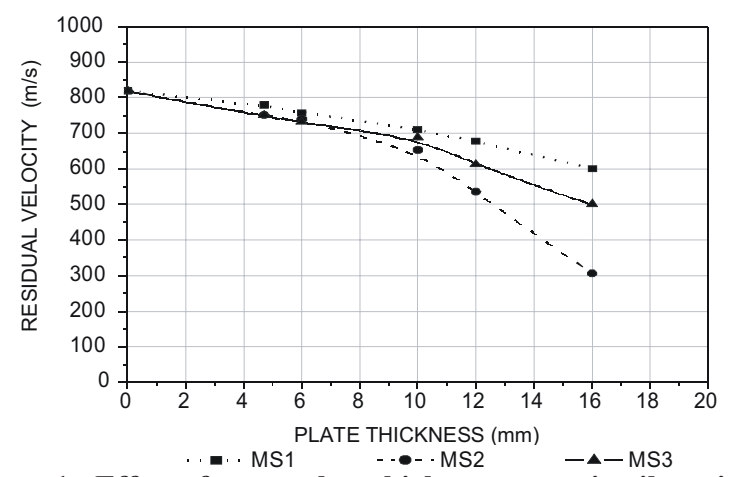

Figure 1. Effect of target plate thickness on projectile residual velocity. thickness, due to somewhat superior yield and tensile properties compared to those of MS3. The patterns of numerically obtained residual velocity variations with plate thickness are similar to the experimental behaviours reported ${ }^{1}$ for similar other cases of plate impact.

\subsection{Effect of Projectile Diameter on Residual Velocity}

The purpose of this study was to verify whether current finite element-based analyses would qualitatively yield experimentally observed variations ${ }^{1}$ of residual velocity wrt impact velocity for projectiles of different diameters while maintaining the ratio of shank length-to-diameter (i.e. 1/d ratio) as constant. The computed responses for $4.7 \mathrm{~mm}$ MS1 plates impacted normally by ogival-nose projectiles of $10 \mathrm{~mm}$ and $15 \mathrm{~mm}$ dia and of a constant $1 / \mathrm{d}$ ratio of 3.6 , are given in Fig. 2. Adequate test data is not available for making a direct comparison with the residual velocity curves shown in Fig. 2, however, their shapes are typically similar to the test-based variations given $^{2}$ and by other researchers for a variety of steel and aluminium target plates. The authors are of the opinion that it would not have been possible to predict the steep drop in residual velocity close to ballistic limit ( $\mathrm{x}$-intercept for a given curve in Fig. 2) as seen in physical ballistic impact tests unless the present finite element modelling approach would have been consistent and robust. Additionally, it is pointed out that using an approach similar to what has been outlined here, Raguraman and Deb $^{3}$ obtained extremely good correspondence of computed ballistic limits with corresponding test-based values. It is shown in a later section that the ballistic limits given in Fig. 2 are in good agreement with those

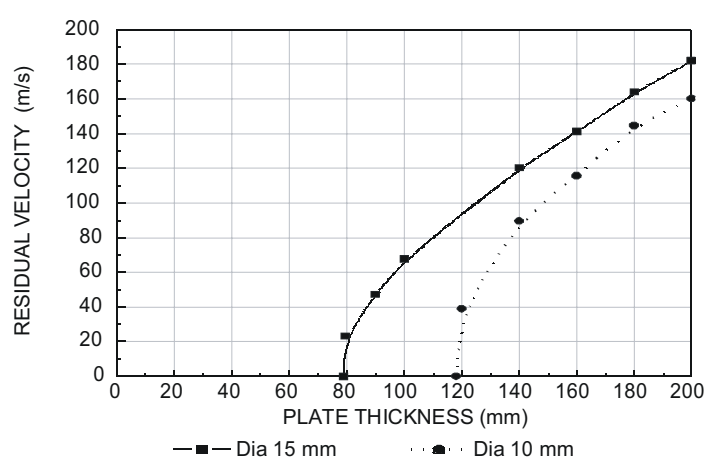

Figure 2. Variations of residual velocity with impact velocity for two projectile diameters. 
predicted by a regression relation ${ }^{4}$ derived based on test data and shear plugging mode of failure of mild steel target plates.

It is pointed out that the ballistic limits in Fig. 2 have been obtained by following a trial-and-error approach, where ballistic limit is interpreted as the maximum impact velocity at which projectile residual velocity for a target plate just becomes zero. Thus, referring to Fig. 3 which depicts velocity time histories of projectiles normally impacting a target plate, $43.5 \mathrm{~m} / \mathrm{s}$ can be considered as the ballistic limit as a slightly higher impact velocity results in a non-zero residual velocity.

\subsubsection{Effect of Projectile Mass on Residual Velocity}

The effect of changing projectile shank length (by keeping diameter as constant) leads to a change in projectile aspect ratio ( $(1 / \mathrm{d})$, and consequently its mass. Since the kinetic energy of a projectile is proportional to its mass, any significant change in the latter is expected to alter its ballistic performance.

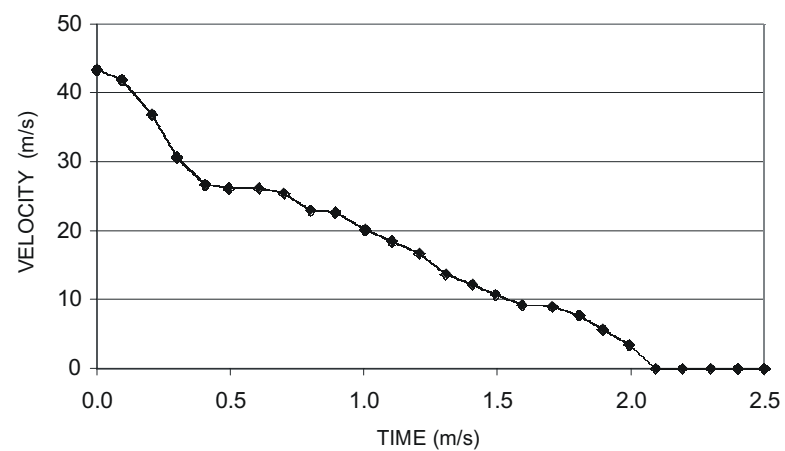

(a)

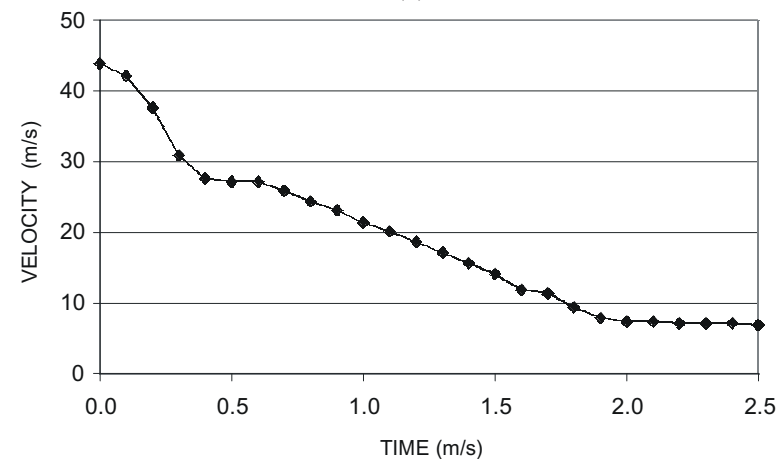

(b)

Figure 3. Computed velocity time histories of projectiles normally impacting a target plate: (a) $43.5 \mathrm{~m} / \mathrm{s}$ and (b) $44 \mathrm{~m} / \mathrm{s}$.
The effect of progressively increasing projectile length, and thereby its mass, is shown in Fig. 4 after analysing impacts with ogival-nosed projectiles on $4.7 \mathrm{~mm}, 10 \mathrm{~mm}$, and $16 \mathrm{~mm}$ plates previously considered (with impact velocities as per Gupta and $\mathrm{Madhu}^{1}$ for these plates). The choice of blunt projectiles is driven by the finding of the section 2.1. that these are likely to yield the highest residual velocity or lowest ballistic limit for a given target. It is seen in Fig. 4 that projectile residual velocity increases prominently in the beginning and then becomes relatively insensitive to increase in projectile mass. The variation of residual velocity with mass in Fig. 4 for a given plate can be said to be equivalent to a drop in ballistic limit initially but gradually reaching a plateau. The latter phenomena were observed in laboratory impact tests by Gupta, Ansari and Gupta $^{2}$ for the aluminium plates.

\subsubsection{Effect of Projectile Nose Shape on Residual Velocity}

The test cases reported by Gupta and Madhu ${ }^{1}$ for mild steel plates, which have been simulated in Part I of the present series, were for impact with ogival-nosed projectiles. The relative performances of projectiles of nose shapes such as conical, hemispherical, and blunt are shown in Fig. 5. The performances of these diverse projectiles for normal impact are studied here using the simulation guidelines previously developed. The geometry and mass $(\sim 5.2 \mathrm{~g})$ of the ogival-nosed projectile considered so far is retained; its length and diameter are used in creating the finite element models of the additional three projectiles with nose shape variations shown in Fig. 5. The mass of each of the projectiles (a), (b), and (c) in Fig. 5 is set equal to that of the ogival-

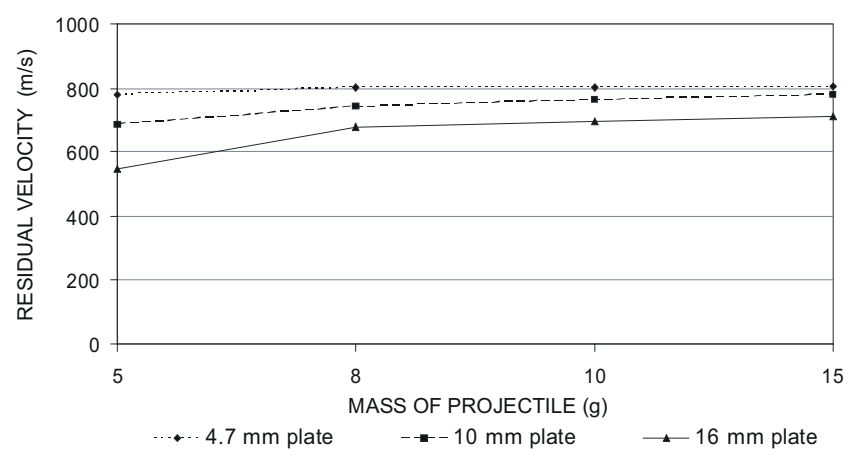

Figure 4. Variations of residual velocity with projectile mass. 


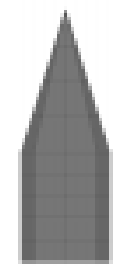

(a) conical

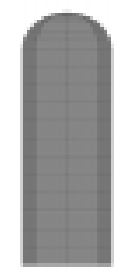

(b) hemispherical

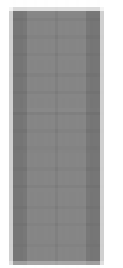

(c) blunt
Figure 5. Different nose shapes of projectiles.

head projectile; for different volumes of the projectiles (a), (b), and (c), this constant mass is achieved by artificially varying the density of the core.

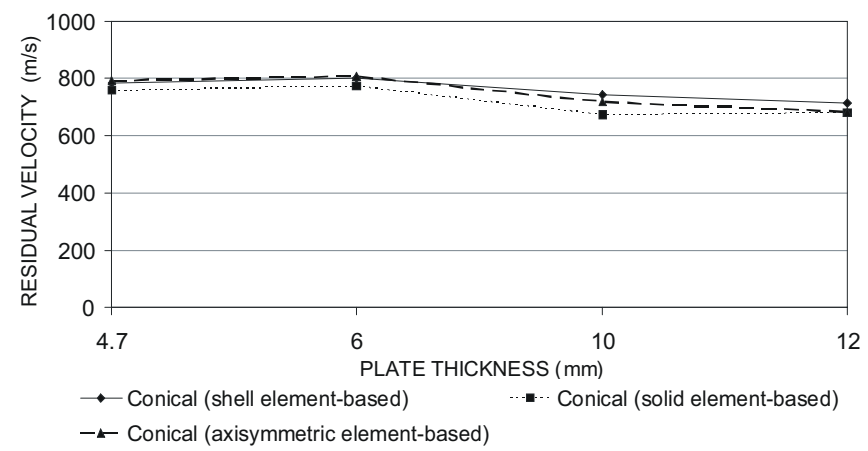

(a)

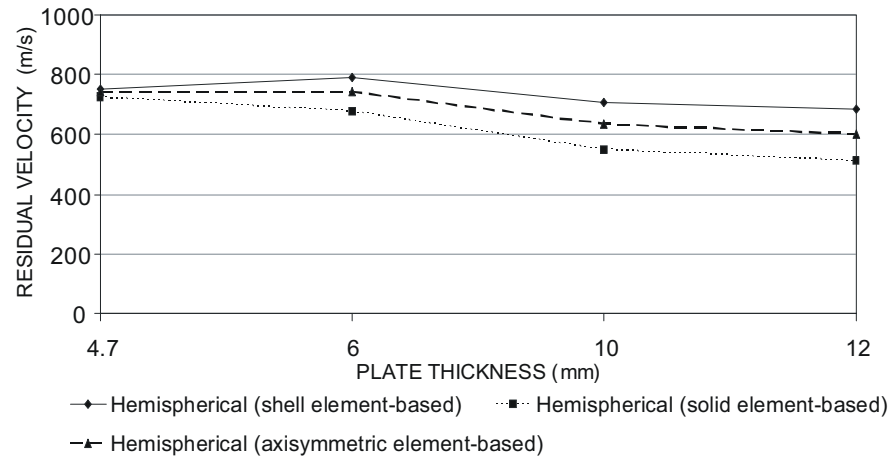

(b)

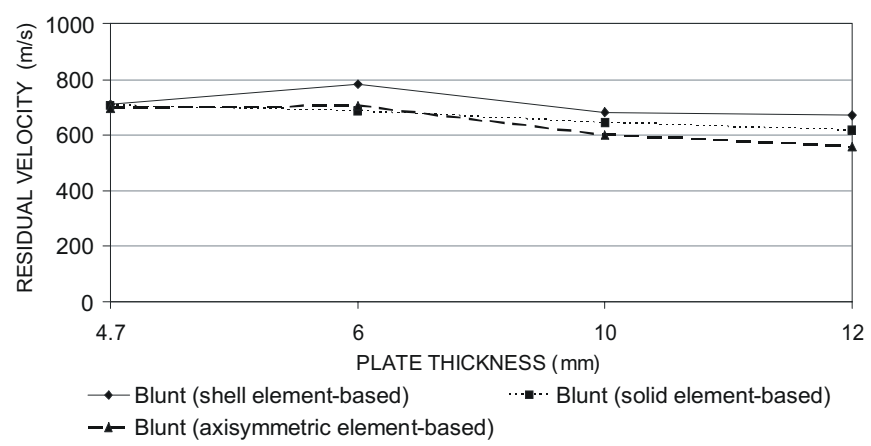

(c)

Figure 6. Residual velocities for projectiles with different nose shapes: (a) conical, (b) hemispherical, and (c) blunt-shaped projectiles.
The variations of computed residual velocities for projectiles of selected nose shapes are shown in Fig. 6 wrt plate thickness. The plates are of the same specifications as defined by Gupta and Madhu ${ }^{1}$ and used in the convergence study in Part I of this series. The impact velocities considered correspond to the test velocities $(820-870 \mathrm{~m} / \mathrm{s})$ mentioned by Gupta and Madhu ${ }^{1}$ of ogival-nosed projectiles for a plate of a given thickness (i.e., 4.7/6/10/12 mm) and material (MS1, MS2 or MS3 according to Gupta and Madhu' ${ }^{1}$.

In Fig. 7, a comparison is made of the residual velocities of projectiles of different nose shapes. Additionally, the comparison is made for residual velocities obtained through the shell-based representation of target plate and axisymmetric finite element modelling. It is seen in Fig. 7 that the computed residual velocities for conical projectiles are always higher than those obtained for hemispherical and blunt Shaped projectiles. Borvik ${ }^{5}$, et al. found through experimental studies that the conical shaped projectiles required less energy to perforate the target at the

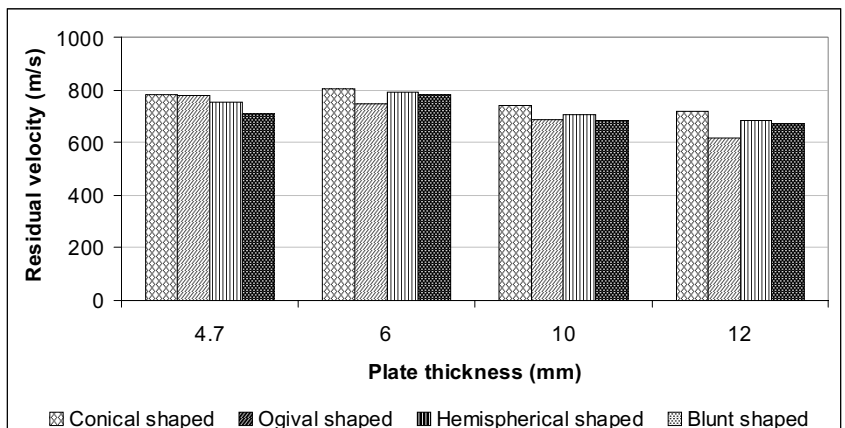

(a)

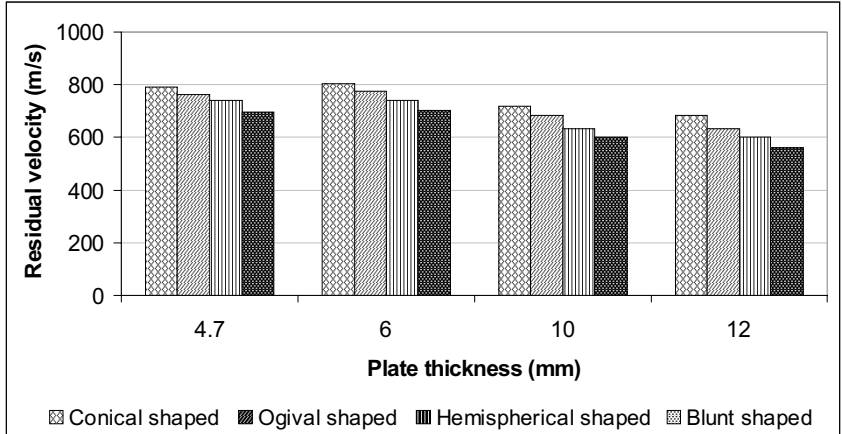

(b)

Figure 7. Comparison of different nose shapes of projectiles (a) shell element-based (b) axisymmetric elementbased. 


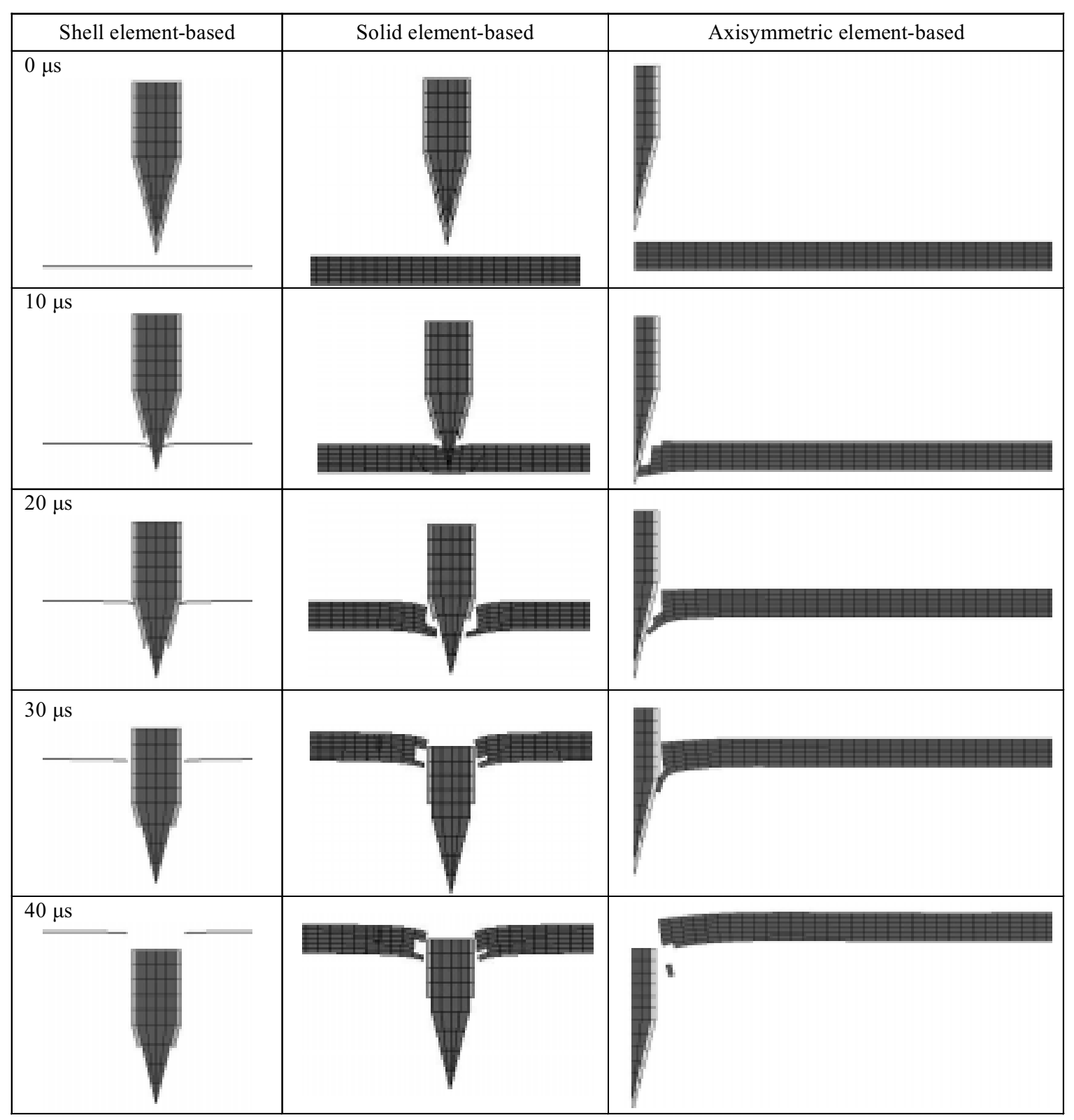

Figure 8. Snap-shots of impact simulation with a conical-head projectile.

higher impact velocities. A similar trend has been found here in Fig.7.

In Fig. 7(a), the variation of residual velocity for projectiles of different nose shapes appears to be most consistent for the $4.7 \mathrm{~mm}$ target plate as the order in which residual velocity varies correlates directly with the pointedness of projectile. On the other hand, for fully axisymmetric modelling, the variation of residual velocity (i.e., highest for conical, followed by ogival, hemispherical, and blunt head projectiles) is consistent for all plates considered, as revealed in Fig. 7(b). Simulationbased failure modes of $4.7 \mathrm{~mm}$ thick MS1 target plates impacted with conical-, hemispherical- and blunt-nosed projectiles obtained using different modelling approaches are shown in Figs 8, 9 and 10 , respectively. A localised bulging was observed at the impact zone for shell-, solid- and axisymmetric element-based representation of target plate which appeared to increase with a reduction in the sharpness of projectile head. The erosion of copper sheath of projectile appeared to be less dependent on projectile nose shape. 


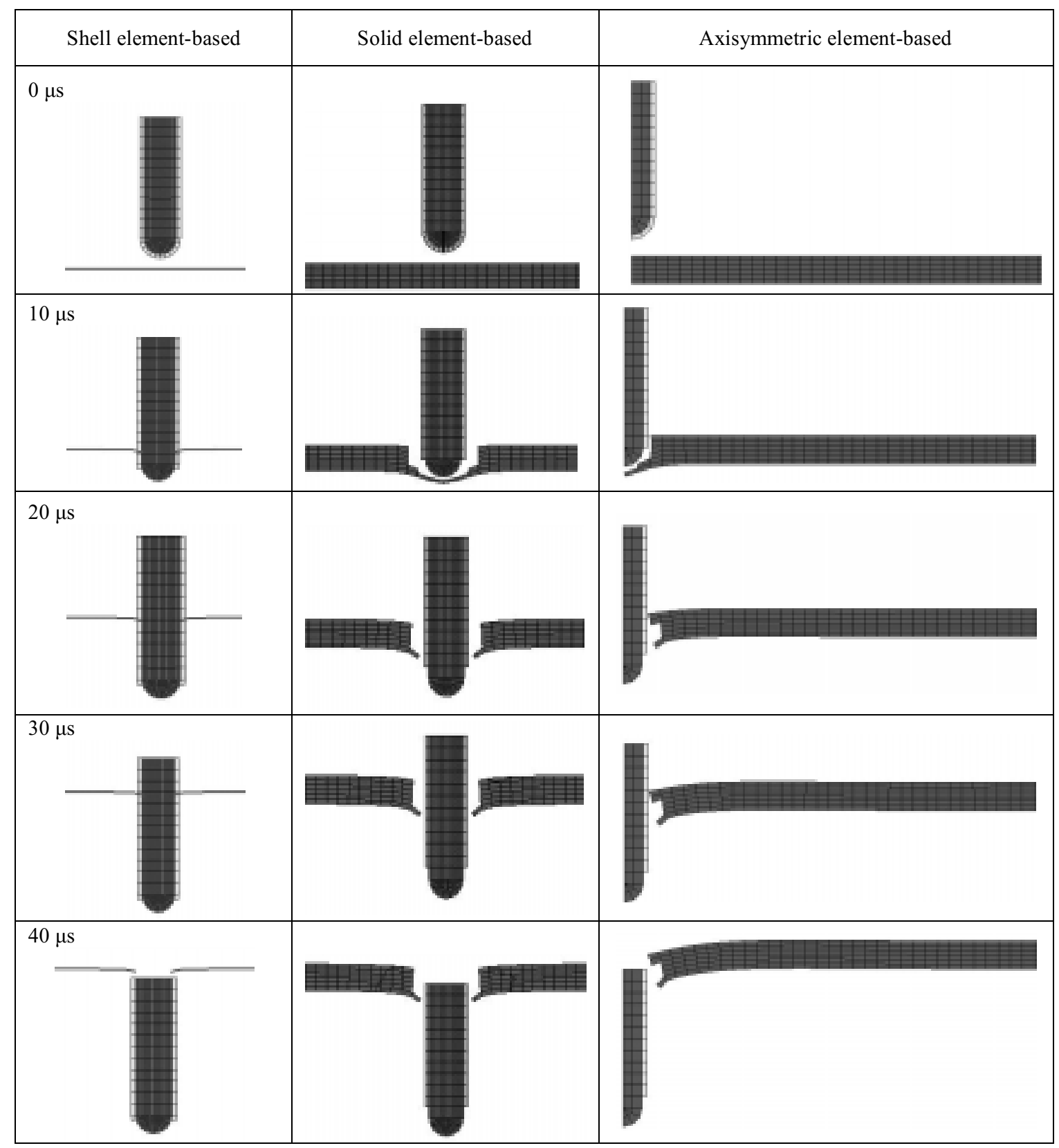

Figure 9. Snap-shots of impact simulation with a hemispherical-head projectile.

\subsubsection{Estimation of Residual Velocity and} Ballistic Limit using a Regression Relation

A regression-based relation for estimation of residual velocity considering the key parameters of plate and projectile has recently been presented by $\mathrm{Deb}^{4}$, et al. and is reproduced below:

$v_{r}=\left[v_{i}^{2}-\frac{2.64 \sigma_{m} d t^{2}}{m_{p} \cos ^{2} \alpha}\right]^{\frac{1}{2}}$ where, $v_{r}$ and $v_{i}$ are respectively residual and impact velocities of projectile, $m_{p}$ is mass of projectile, $\sigma_{m}$ is the average of yield and failure strengths of target plate, $d$ is projectile diameter, $t$ is thickness of target plate, and $\alpha$ is angle of obliquity of projectile axis wrt plate normal. In Eqn (1), the constant 2.64 is obtained by regression analysis of test data for normal and oblique impact of jacketed ogival-nosed projectiles on mild steel plates. It should be noted that in Eqn (1) should be set to zero for normal impact of projectile on 
RAGURAMAN, et al.: PROJECTILE IMPACT ON MILD STEEL ARMOUR PLATES

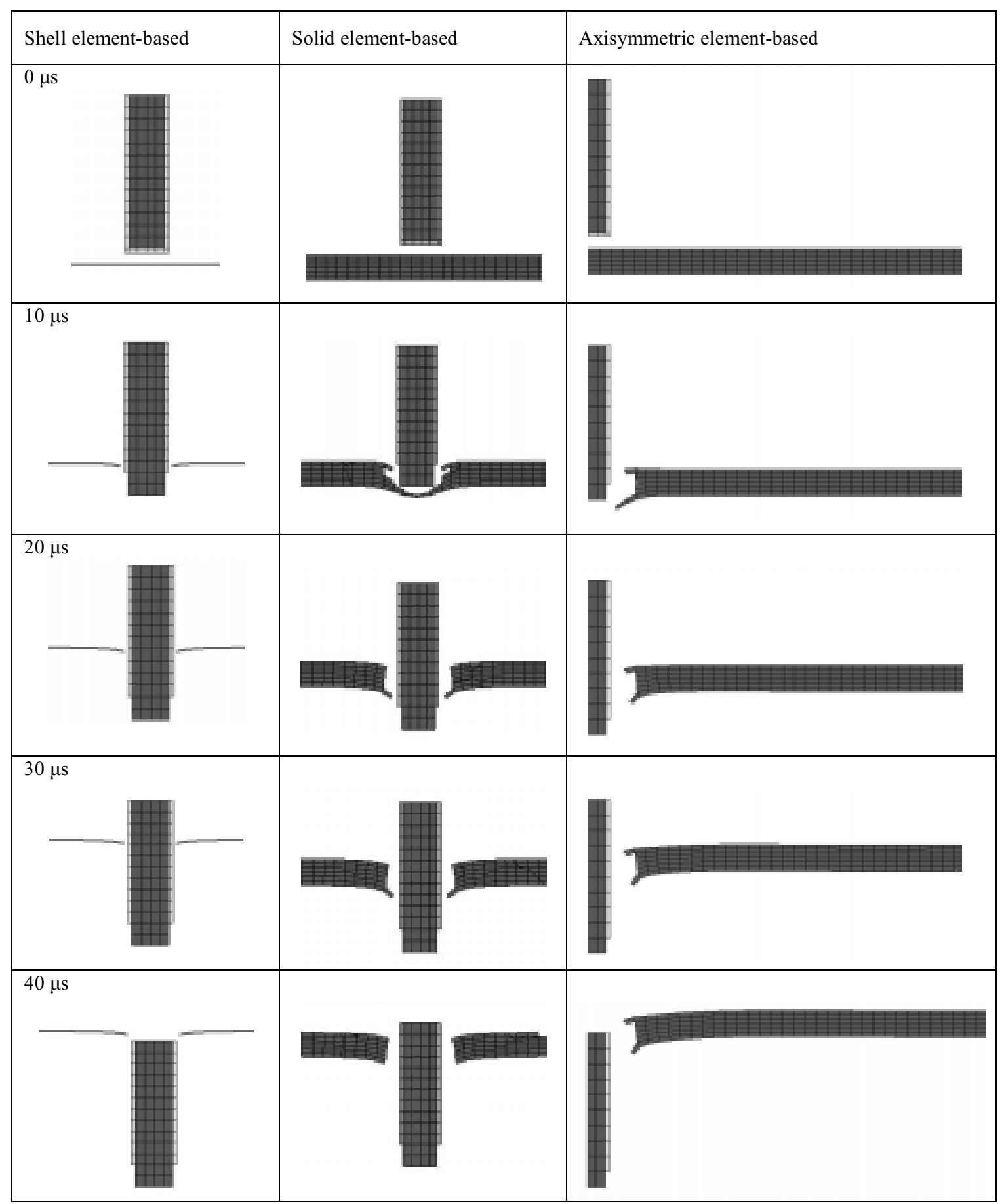

Figure 10. Snap-shots of impact simulation with a blunt projectile.

a target plate. The predicted values as per Eqn (1) for various impact cases considered in the present study are given in Table 1. It is readily seen from this table that the residual velocities yielded by Eqn (1) correlate well with the corresponding test values given by Gupta ${ }^{1}$.Ballistic limit, $V_{b l}$ for a given mild steel target plate can be obtained from Eqn (1) by setting $V_{r}=0$, so that $V_{i}=V_{b l}$. Thus

$$
V_{b l}=\left[\frac{2.64 \sigma_{m} d t^{2}}{m_{p} \cos ^{2} \alpha}\right]^{\frac{1}{2}}
$$


DEF SCI J, VOL. 58, NO. 4, JULY 2008

Table 1. Comparison of test-based and computed residual velocities

\begin{tabular}{|c|c|c|c|c|c|}
\hline \multirow{2}{*}{$\begin{array}{c}\text { Plate } \\
\text { material in } \\
\text { Ref. } 1\end{array}$} & \multirow{2}{*}{$\begin{array}{l}\text { Average quasi- } \\
\text { static strength, } \sigma_{m} \\
\text { (MPa) }\end{array}$} & \multirow{2}{*}{$\begin{array}{l}\text { Plate thickness, } t \\
\text { (mm) }\end{array}$} & \multirow{2}{*}{$\begin{array}{c}\text { Impact velocity, } v_{i} \\
(\mathrm{~m} / \mathrm{s})\end{array}$} & \multicolumn{2}{|c|}{ Residual velocity, $v_{r}(\mathbf{m} / \mathbf{s})$} \\
\hline & & & & Test Ref. 1 & Computed using Eqn. (1) \\
\hline MS1 & 340.0 & 4.7 & 821.0 & 758.6 & 806.3 \\
\hline \multirow[t]{2}{*}{ MS2 } & 521.0 & 6.0 & 866.3 & 792.2 & 837.3 \\
\hline & & 10.0 & 827.5 & 702.2 & 732.9 \\
\hline \multirow[t]{2}{*}{ MS3 } & 464.0 & 12.0 & 818.0 & 661.5 & 675.7 \\
\hline & & 16.0 & 819.7 & 562.0 & 542.3 \\
\hline
\end{tabular}

Table 2. Comparison of predicted ballistic limits for $4.7 \mathrm{~mm}$ thick MS1 target plate

\begin{tabular}{|c|c|c|c|c|c|c|}
\hline \multirow{2}{*}{$\begin{array}{c}\text { Average } \\
\text { strength, } \sigma_{m}, \\
\text { of MS1 plate } \\
(\mathrm{MPa})\end{array}$} & \multirow{2}{*}{$\begin{array}{c}\text { Plate } \\
\text { thickness, } t \\
(\mathbf{m m})\end{array}$} & \multirow{2}{*}{$\begin{array}{l}\text { Projectile dia }, d \\
(\mathbf{m m})\end{array}$} & \multirow{2}{*}{$\begin{array}{c}\text { Projectile mass, } \\
m_{p}(\mathrm{~g})\end{array}$} & \multicolumn{2}{|c|}{ Ballistic limit (m/s) } & \multirow{2}{*}{$\begin{array}{l}\text { Percentage difference in } \\
\text { predicted ballistic limits }\end{array}$} \\
\hline & & & & $\begin{array}{c}\text { Numerically } \\
\text { predicted } \\
\text { (from Fig. 2) }\end{array}$ & $\begin{array}{c}\text { Computed using } \\
\text { Eqn.(2) }\end{array}$ & \\
\hline \multirow{2}{*}{340} & \multirow{2}{*}{4.7} & 10 & 11.1 & 118.0 & 122.0 & 3.4 \\
\hline & & 15 & 37.6 & 79.0 & 81.1 & 2.7 \\
\hline
\end{tabular}

Ballistic limits predicted by Eqn (2) for the cases considered in Fig. 2 are listed in Table 2. It is readily seen from this table that the ballistic limits based on Eqn (2) compare extremely well with the corresponding simulation-based values. This correlation provides a mutual confirmation of the effectiveness of Eqn (2) as well as the numerically obtained ballistic limits of Fig. 2 .

\section{CONCLUSIONS}

The power of simulation as a tool for assessing performance of target plates for various geometric parameters of plate and projectile has been aptly demonstrated in Part II of the present two-part series. The current numerical studies have led to the trends consistent with earlier experimentallyobserved behaviours for similar impact problems. Additionally, it has been shown that numerically computed ballistic limits compare favourably with the corresponding predictions obtained from a regression-based relation. Thus, it can be concluded that the study reported in the present paper establishes one's confidence in the reliability of LS-DYNAbased analysis with the proposed modelling techniques as a predictive tool for design of steel armour plates subject to projectile ballistic impact.

\section{ACKNOWLEDGEMENTS}

The authors are thankful to the Secretary, Armament Research Board (ARMREB), DRDO, Govt of India, for sponsoring the work reported in this paperand to $\mathrm{Mr}$ M.D. Upadhyay, AD, ARMREB, for his interest, advice, and encouragement that greatly aided in the successful completion of the work.

\section{REFERENCES}

1. Gupta, N.K. \& Madhu, V. An experimental study of normal and oblique impact of hardcore projectile on single and layered plates. Int. J. Impact. Engg., 1992, 19, 395-414.

2. Gupta, N.K.; Ansari, R. \& Gupta, S.K. Normal impact of ogival nosed projectiles on thin plates. Int. J. Impact Engg., 2001, 25, 641-60.

3. Raguraman, M. \& Deb, A. Robust prediction of residual velocities and ballistic limits of projectiles for impact on thin aluminium plates. In Proceedings of $9^{\text {th }}$ International Conference on Structures Under Shock and Impact (SUSI), 2006. pp. 205-14.

4. Deb, A.; Raguraman, M. \& Gupta, N.K. Simulation of oblique impact of jacketed hardened-core projectiles on mild steel plates. In Proceedings of Symposium on Plasticity and Impact Mechanics (IMPLAST), 2007. pp. 631-38.

5. Borvik, T., et al. Perforation of $12 \mathrm{~mm}$ thick steel plates by $20 \mathrm{~mm}$ diameter projectiles with flat, hemispherical, and conical noses: Part I: Experimental study. J. Impact Engg., 1992, 27, 19-35. 


\section{Contributors}
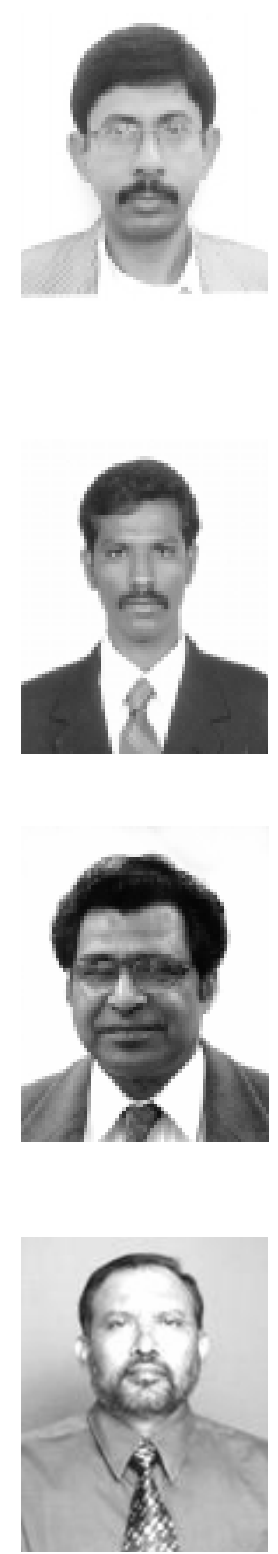

Dr Anindya Deb obtained his ME from the Memorial University of Newfoundland, St. John's, Canada and PhD from the State University of New York at Buffalo. Presently, he is a Professor at the Centre for Product Design and Manufacturing, Indian Institute of Science (IISc), Bangalore. His interests are in the areas of CAE in product design, crashworthiness of transportation systems and occupant safety, impact modelling and testing, design of automotive systems, and hybrid methods in design. He obtained four patents on vehicle head impact safety countermeasures and one Indian design registration on a lightweight car, and has published a number of papers in international journals and conference proceedings.

Mr M. Raguraman received his ME (Production Engineering) from the PSG College of Technology, Coimbatore. He has recently completed his $\mathrm{PhD}$ at the Indian Institute of Science, Bangalore, in the area of CAE-driven design of metallic armour plates for ballistic impact. He has now taken up a research position at the School of Mechanical Engineering, University of Leeds, UK.

Prof N.K. Gupta is serving as a Henry Ford Chair Emeritus Professor in IIT, Delhi since 2005. He has been with the Dept of Applied Mechanics, IIT Delhi since 1971. He works in the area of large deformations of metals and composites at low, medium, and high rates of loading. He has published his researches extensively in national and international journals, and undertaken national and international research and consultancy projects. He is a Fellow of the Indian National Science Academy, the Indian National Academy of Engineering, the National Academy of Sciences, India, the Aeronautical Society of India, and the Institution of Engineers.

Dr D.K. Kharat is working at the Armament Research and Development Establishment, Pune. He is Group Director, Air Armament, DRDO Centre for Piezoceramics and Devices, and Futuristic Weapon Technology Divisions. He has 75 research papers published in peer-reviewed journals and various seminars. He is a $\mathrm{PhD}$ research guide at the University of Pune and Defence Institute of Armament Technology, Pune. 